\title{
Infections of GBS's etiology and use of perinatal antibiotic prophylaxis
}

\author{
Sławomir Szymański ${ }^{1}$, Katarzyna Szczerba², Violetta Konstanty- Kurkiewicz ${ }^{3}$, \\ Agata Daszkiewicz ${ }^{4}$, Olimpia Sipak- Szmigiel ${ }^{1}$ \\ ${ }^{1}$ Chair and Department of Obstetrics and Pathology of Pregnancy, Pomeranian Medical University, Szczecin, Poland \\ 2 Obstetrics and Gynecology Ward of SPZOZ Hospital, Kołobrzeg, Poland \\ ${ }^{3}$ Department of Obstetrics and Gynecology, Pomeranian Medical University, Szczecin, Poland \\ ${ }^{4}$ Independent Laboratory of Obstetric Skills, Pomeranian Medical University, Szczecin, Poland
}

Szymański S, Szczerba K, Konstanty-Kurkiewicz V, Daszkiewicz A, Sipak- Szmigiel O. Infections of GBS's etiology and use of perinatal antibiotic prophylaxis. J Pre-Clin Clin Res. 2018; 12(2): 54-58. doi: 10.26444/jpccr/92278

\section{Abstract}

Introduction. A significant decline in the proportion of perinatal mortality of foetuses and newborns have been reported in recent years. Despite the tremendous progress made in the field of perinatal care, there is still a risk of infection of the foetus during pregnancy or its birth.

Objective. The aim of the study was to assess the effectiveness of an antibiotic prophylaxis in order to reduce perinatal percentage of early-symptomatic infections in newborn infants.

Materials and method. Material for the study was obtained from the medical records of 1,328 live born individual infants and their mothers. Tested continuous parameters were described with the appropriate numbers, arithmetic mean, standard deviation, median and minimum and maximum values. For analysis of fractions the Chi square was used; also with Yates correction (for a small number of cells). Level of statistical significance $-p<0.05$.

Results. The duration of pregnancy in mothers who gave birth to newborns without evidence of GBS infection was significantly longer than the duration of pregnancy in mothers whose infants were infected with Group B streptococcus (GBS) (39.2 vs 38.3 weeks gestation). In 13 infants infected during delivery, antibiotic prophylaxis was not used (92.86\%), while it was used in only one case (7.14\%). Perinatal prophylaxis was used in $26.81 \%$ of the surveyed mothers.

Conclusions. The use of maternal antibiotic prophylaxis can have an impact on lowering the percentage of GBS infections in newborn infants. A trend of reducing the proportion of earlysymptomatic infections has been observedin recent years. The type of delivery does not seem to have a decisive influence on the incidence of GBS- based infection. The colour of the amniotic fluid does not determine the presence of the GBS infection.

\section{Key words}

carrier of the GBS, childbirth, antibiotics, infection

\section{INTRODUCTION}

A significant decline in the proportion of perinatal mortality of foetuses and newborns have been reported in recent years. Despite the tremendous progress made in the field of perinatal care, there is still a risk of infection of the foetus during pregnancy or its birth. Streptococci, particularly Group B streptococcus (GBS) - Streptococcus agalactiae is the main causative agent of such infection $[1,2]$. However, the use of intrapartum antibiotic prophylaxis can largely overcome the effects of carriers of this pathogen in the urogenital tract of a pregnant woman. In everyday work, an obstetrician most often encounters the above-mentioned infections that cause complications in the course of pregnancy. They are one of the main causes of morbidity and mortality of newborns. In pregnant women there is a huge risk of the following complications: premature delivery, premature rupture of the membranes, infection and septic shock, and in the foetus: hypotrophy, premature birth, and even death in the neonatal period.

Address for correspondence: Sławomir Szymański, Zakład Położnictwa i Patologii Ciąży Pomorski Uniwersytet Medyczny, ul. Żołnierska 48, 71-210 Szczecin

Tel. (91) 48009 83, tel. kom. 604-970-670

e-mail: sszymanski@o2.pl

Received:???; accepted:???

\section{OBJECTIVE}

The aim of the study was to assess the effectiveness of an antibiotic prophylaxis in order to reduce the perinatal percentage of early-symptomatic infections in newborn infants.

\section{MATERIALS AND METHOD}

Material for the study was obtained from the medical records of 1,328 live born individual infants and their mothers. Births covered by the survey were took place at the Regional Hospital in Kolobrzeg in 2011 (at the time of introduction into the daily practice the therapeutic guidelines of PTG for prevention of GBS infections in newborns) and in 2007 (when there was no a widespread use of prevention of GBS infections among newborns). These years were selected randomly, but in such a way as to be able to assess the implementation, effectiveness and universality of the use of perinatal antibiotic prophylaxis (IAP). The study was approved by the Bioethical Committee of the Pomeranian Medical University in Szczecin (KB0012/65/06/2013).

Statistical analysis was carried using Statistica PL v. 10.0 StatSoft, USA. Parameters measured continuously were described with appropriate numbers, arithmetic mean, 
standard deviation, median, minimum and maximum values. Discrete parameters (qualitative) were shown as percentages of the corresponding ones (fractions). ShapiroWilk test verified the normality of distributions, and when the situation arose logarithmic transformation was used. Arithmetic means between groups were compared with t-Student test. The scale of Apgar between groups was compared with non-parametric Mann-Whitney U test. For analysis of the fractions, Chi2 test was used; also with Yates correction (for a small number of cells). The level of statistical significance was $\mathrm{p}<0.05$.

\section{RESULTS}

The duration of pregnancy of mothers of newborns without GBS infection was significantly longer than the duration of pregnancy of mothers of infants infected with GBS ( $p<0.03)$. Hospitalization time of a newborn infected with GBS and born vaginally was significantly longer than a non-infected newborn $(\mathrm{p}<0.0001)$. Hospitalization time of a newborn infected with GBS and born by cesarean section was significantly longer than a non-infected newborn $(\mathrm{p}<0.002)$. The condition of a newborn evaluated by Apgar scoring was significantly higher in infants without GBS infection, than in those infected $(\mathrm{p}<0.03)$. Differences regarding body weight of infants were not statistically significant (Tab.1).

Table 1. General parameters relating to: pregnancy and the newborn. and the occurrence of GBS infections in newborn

\begin{tabular}{|c|c|c|c|c|c|c|c|}
\hline & \multicolumn{6}{|c|}{ Newborn } & \multirow[t]{3}{*}{$\mathrm{p}^{*}$} \\
\hline & \multicolumn{3}{|c|}{ Uninfected } & \multicolumn{3}{|c|}{ Infected } & \\
\hline & Mean & SD & $\mathrm{N}$ & Mean & SD & $\mathrm{N}$ & \\
\hline Duration of pregnancy (weeks) & 39.2 & 1.6 & 1314 & 38.3 & 2.5 & 14 & $<0.03$ \\
\hline $\begin{array}{l}\text { Hospitalization of newborn } \\
\text { after vaginal delivery (in days) }\end{array}$ & 3.9 & 2 & 1052 & 11 & 3.5 & 12 & $<0.0001$ \\
\hline $\begin{array}{l}\text { Hospitalization of newborn } \\
\text { after cesarean section (in days) }\end{array}$ & 5.7 & 2.1 & 262 & 10.5 & 2.1 & 2 & $<0.002$ \\
\hline $\begin{array}{l}\text { Evaluation of newborn with } \\
\text { Apgar score }\end{array}$ & 9.2 & 1.2 & 1314 & 8.5 & 1.2 & 14 & $<0.03$ \\
\hline Neonates' body weight (grams) & 3382 & 522 & 1314 & 3275 & 625 & 14 & NS \\
\hline
\end{tabular}

$\mathrm{N}$ - amount of studied population; SD - standard deviation

* t-student test

A total of 14 newborns (1.05\%) who had an infection of GBS etiology 78.57\% came from mothers who had not taken a GBS smear, $14.29 \%$ were born by mothers who had a negative smear, and $17.14 \%$ who had a positive test. The differences were not statistically significant (Tab. 2).

Table 2. Outcome of smear GBS in pregnant women and presence of GBS infection in the newborn

\begin{tabular}{lcccccc}
\hline & \multicolumn{6}{c}{ Score of GBS in pregnant women } \\
\cline { 2 - 7 } & \multicolumn{2}{c}{ Lack of smear } & \multicolumn{2}{c}{ Negative } & \multicolumn{2}{c}{ Positive } \\
\cline { 2 - 7 } & $\mathrm{n}$ & $\%$ & $\mathrm{n}$ & $\%$ & $\mathrm{n}$ & $\%$ \\
\hline Uninfected & 833 & 63.39 & 329 & 25.04 & 152 & 11.57 \\
\hline Infected & 11 & 78.57 & 2 & 14.29 & 1 & 7.14 \\
\hline Total & 844 & 63.55 & 331 & 24.92 & 153 & 11.52 \\
\hline NS* & & & & & &
\end{tabular}

Chi-square test
In $92.86 \%$ of the infected newborns, antibiotic prophylaxis was not used. Differences were close to statistical significance $(\mathrm{p}=0.0949)$ (Tab. 3).

Table 3. Application of perinatal antibiotic prophylaxis (IAP) in pregnancy and occurrence of GBS infection in the newborn

\begin{tabular}{lcccccc}
\hline & \multicolumn{2}{c}{ Uninfected } & \multicolumn{2}{c}{ Infected } & \multicolumn{2}{c}{ Total } \\
\cline { 2 - 8 } & $\mathrm{n}$ & $\%$ & $\mathrm{n}$ & $\%$ & $\mathrm{~N}$ & $\%$ \\
\hline No IAP & 959 & 72.98 & 13 & 92.86 & 972 & 73.19 \\
\hline IAP & 355 & 27.02 & 1 & 7.14 & 356 & 26.81 \\
\hline \multicolumn{1}{c}{$\mathrm{p}=0.0949$} & & & & & & \\
\hline Chi-square test & & & & & &
\end{tabular}

In the group without GBS result, the IAP was used in $23.29 \%$ cases, and infected infants were observed only in the group without IAP. Differences were close to statistical significance $(\mathrm{p}=0.0681)$. Among GBS-negative mothers, in $87.23 \%$ of cases IAP was not used while in $12.77 \%$ it was applied. In the group without IAP, GBS infection occurred twice. The differences were not statistically significant. In the group of GBS-positive mothers, one infant (0.83\%) was diagnosed postpartum with intrauterine infection of GBS etiology. IAP was not applied in $21.71 \%$ of GBS positive mothers. The differences were not statistically significant (Tab. 4).

Table 4. Evaluation of correlation between GBS test result, occurrence of infection in newborn and use of IAP

\begin{tabular}{lccccccc}
\hline & \multicolumn{2}{c}{ Uninfected } & \multicolumn{2}{c}{ Infected } & \multicolumn{2}{c}{ Total } & \multirow{2}{*}{$\begin{array}{c}\text { f from the row } \\
\text { (the N) }\end{array}$} \\
\cline { 2 - 6 } & $\mathrm{n}$ & $\%$ & $\mathrm{n}$ & $\%$ & $\mathrm{~N}$ & $\%$ & \\
\hline No IAP & 639 & 76.71 & 11 & 100 & 650 & 77.01 & $98.31 / 1.69$ \\
\hline IAP & 194 & 23.29 & 0 & 0 & 194 & 22.99 & $100.00 / 0.00$ \\
\hline Total & 833 & 100 & 11 & 100 & 844 & 100 & $98.70 / 1.30$ \\
\hline p=0.0681 & & & & & & & \\
\hline No IAP & 287 & 87.23 & 2 & 100 & 289 & 87.31 & $99.31 / 0.69$ \\
\hline IAP & 42 & 12.77 & 0 & 0 & 42 & 12.69 & $100.00 / 0.00$ \\
\hline Total & 329 & 100 & 2 & 100 & 331 & 100 & $99.40 / 0.60$ \\
\hline NS* & & & & & & & \\
\hline No IAP & 33 & 21.71 & 0 & 0 & 33 & 21.57 & $100.00 / 0.00$ \\
\hline IAP & 119 & 78.29 & 1 & 100 & 120 & 78.43 & $99.17 / 0.83$ \\
\hline Total & 152 & 100 & 1 & 100 & 153 & 100 & $99.35 / 0.65$ \\
\hline NS* & & & & & & & \\
\hline
\end{tabular}

Chi-square test

The current study also analyzed the manner of delivery and colour of the amniotic fluid (Tab. 5 and 6). Among all uninfected with GBS infants, $80.06 \%$ were born vaginally and $19.94 \%$ through a caesarean section. Of all infants with GBS infection, $85.71 \%$ were born vaginally while $14.29 \%$ through a caesarean section. The differences were not statistically significant (Tab. 5). Among all those uninfected with GBS infants, 90.09\% were born with clear amniotic fluid, while $9.91 \%$ had green fluid. The differences were not statistically significant (Tab. 6). 
Table 5. Method of completion of delivery and incidence of infants'GBS infection

\begin{tabular}{cccccccc}
\hline & \multicolumn{2}{c}{ Uninfected } & \multicolumn{2}{c}{ Infected } & \multicolumn{2}{c}{ Total } & \multirow{2}{*}{$\begin{array}{c}\text { \% from the row } \\
\text { (the N) }\end{array}$} \\
\cline { 2 - 6 } & $\mathrm{n}$ & $\%$ & $\mathrm{n}$ & $\%$ & $\mathrm{~N}$ & $\%$ & \\
\hline VD & 1052 & 80.06 & 12 & 85.71 & 1064 & 80.12 & $98.87 / 1.13$ \\
\hline CS & 262 & 19.94 & 2 & 14.29 & 264 & 19.88 & $99.24 / 0.76$ \\
\hline Total & 1314 & 100 & 14 & 100 & 1328 & 100 & $98.95 / 1.05$ \\
\hline
\end{tabular}

Chi-square test; ${ }^{*} \mathrm{NS}$; VD- vaginal delivery; CS- cesarian section

Table 6. Colour of amniotic fluid and morbidity of infants on GBS infection

\begin{tabular}{cccccccc}
\hline & \multicolumn{2}{c}{ Uninfected } & \multicolumn{2}{c}{ Infected } & Total & \multirow{2}{*}{$\begin{array}{l}\text { \% from the } \\
\text { row (the N) }\end{array}$} \\
\cline { 2 - 5 } & $\mathrm{n}$ & $\%$ & $\mathrm{n}$ & $\%$ & $\mathrm{~N}$ & $\%$ & \\
\hline Clear & 1184 & 90.09 & 11 & 78.57 & 1195 & 89.97 & $99.08 / 0.92$ \\
\hline Green & 130 & 9.91 & 3 & 21.43 & 133 & 10.03 & $97.74 / 2.26$ \\
\hline Total & 1314 & 100 & 14 & 100 & 1328 & 100 & $98.94 / 1.06$ \\
\hline
\end{tabular}

NS*

Chi-square test

\section{DISCUSSION}

During birth, the newborn can be colonized by bacteria that live in the reproductive tract of the mother. It has been reported that $30-70 \%$ of neonates born from mothers who were GBS-carriers become colonized via vertical transmission during childbirth [3]. Early symptoms of streptococcal infection in $90 \%$ of cases show up to 72 hours after birth, and affects $1-2 \%$ of the newborn, and derived from GBS positive mothers [3, 4]. Early symptomatic GBS infections are a major cause of perinatal mortality rate of newborns. It was found that, for GBS-positive women there is a 25-fold increased risk of having an infected infant, compared with GBS-negative women [5]. In this study, among the 153 BGS-positive, only one gave birth to a newborn $(0.65 \%)$ who presented earlysymptomatic GBS infection. Numerous reports worldwide confirm that perinatal prophylactic antibiotic therapy in GBS-positive pregnant women, introduced into clinical practice as recommendations Centers for Disease Control and Prevention (CDC), in more than $70 \%$ decreased the occurrence of early-symptomatic GBS infections in newborns $[6,7]$. According to a CDC report from 2007, after the introduction of guidelines for the prevention of early GBS infections in newborns, the proportion of those infections in 2003-2005 were 33\% lower than in 2000-2001 [2, 8].

Velaphi et al. found that after the introduction of the guidelines by the CDC the number of early-symptomatic GBS infection in newborns decreased by $76 \%$ [9] over the 5 -year follow-up. In a retrospective study analyzing data from 67,260 infants born in 1997-2003 in a Boston hospitals (USA), Puopolo et al. found that the use of perinatal antibiotic prophylaxis, according to the adopted CDC protocols, resulted in a significant decrease in the number of severe early-symptomatic infections in newborns, such as sepsis or meningitis, [10]. In a 2012 study Schrag et al. was estimated that in the USA the incidence of invasive early-symptomatic GBS infection decreased from 1.8 cases per 1,000 live births in the early 1990 s, to 0.26 per 1,000 live births in 2010 (ie. more than $80 \%)$. It was calculated that in the USA between 19942010 , more than 70,000 cases of severe early-symptomatic GBS infection were avoided. It was also shown that the effectiveness of IAP in the control of early-onset GBS sepsis is as effective in term babies as well as prematurely born, and fluctuates around 90\% [11]. The American experience shows that the use of a single screening combined with IAP in GBS-colonized women in labour is a highly effective strategy in the fight against early-symptomatic GBS infections in newborns $[2,8]$.

In the presented study it was observed that infants with GBS infection came with similar frequency from both GBS positive mothers, negative, or of unknown outcome swab (7.14\% vs. $14.29 \%$ vs. $78.57 \%, \mathrm{P}=\mathrm{NS}$ ). It was noted, however, that in the group of 972 pregnant women not treated during childbirth, 13 (1.34\%) infants were born with GBS infection, while in the group of 356 mothers treated prenatally with antibiotic only $1(0.28 \%)$ infant was born with congenital infection caused by GBS. It was additinally observed that after the introduction of the mandatory use of perinatal antibiotic prophylaxis, the number of early-symptomatic GBS infection in newborns has dropped from $1.53 \%$ in 2007 to $0.50 \%$ in 2011 ( $\mathrm{p}=0.0672$ ). Valkenburg-van den Berg found that collecting swabs between 35-37 weeks of pregnancy, in accordance with CDC guidelines, has its own limitations. It was shown that at this stage of pregnancy about $6 \%$ of pregnant women colonized by GBS had negative results of cultures towards GBS [12].

In 2010, Berardi et al. published a study in which they found that the majority of reported cases of early-symptomatic GBS infection in 2003-2008 were related to infants born to mothers whose screening results in the carrier S. agalactiae was negative, therefore perinatal antibiotic therapy was not used [13]. In 1983, Boyer et al. showed that 13 out of 47 surveyed women diagnosed with GBS between the 30th-34th week of pregnancy, had negative results of these cultures during labour [14]. Similar observations were made by Assefa [15]. In the Feng-Ying et al. study, 4,696 women gave birth in the 3 hospitals in Texas and California of whom $93.3 \%$ of all carriers of GBS received IAP [16]. At this time, in 2 neonates, i.e. $0.36 / 1,000$ births, were reported as having etiology of GBS sepsis. One of them came from a mother tested negative prenatally towards of GBS carrier, while the second baby came from a mother who was not covered by that screening.

The current shows that approx. 10\% of GBS negative pregnant women at 35-37 gestational age became positive just before giving birth. It was also observed that $35.50 \%$ of pregnant women positive of GBS at 35-37 weeks, and who had received antibiotics during labour, became GBSnegative (smear culture taken at the beginning of delivery, but the result was obtained after its completion). There are some studies that have reported that as many as $61-82 \%$ of newborns with EOS-of GBS (early-onset of GBS sepsis) came from mothers of GBS negative $[10,17,18]$. In the presented study, 14 newborns were found with an early symptomatic of GBS infection, and 2 infants (14.29\%) were born to mothers who were GBS negative, in whom no perinatal antibiotic prophylaxis was used.

The above-mentioned studies strongly suggest that due to the occurrence of spontaneous decolonization and the associated differences between carriers of GBS observed during pregnancy and childbirth, there is a need for rapid, highly specific and sensitive tests for identifying carriers of GBS, which could be implemented at the onset of a labour. The most useful seem to be PCR-based tests for determining DNA of bacteria. Attempts were made to use rapid diagnostic 
tests to detect of GBS antigen directly in the downloaded material, but their sensitivity was too low [19-21]. In this case, immunization of mothers in the form of vaccination appears to be the best solution in future.

Bearing in mind that the high efficiency of perinatal antibiotic prophylaxis observed in most studies in combating early-symptomatic GBS infection in newborns, the conclusions arising from the Cochrane review from 2009 are very surprising. It was assessed that the effectiveness of the IAP is not supported by any credible scientific evidence, and the few studies conducted in this regard have been performed incorrectly. The review also points out that the use of antibiotics on a large scale may causes an increase in drug-resistant bacteria and, therefore, can expose infants to the occurrence of infections caused by antibiotic-resistant strains [22].

Reports from medical literature differently evaluate the relationship between GBS colonization of the reproductive tract pregnant and unfavourable outcome of pregnancy. Many authors have shown a relationship between the colonization of the newborn and the mother's genital tract by S. agalactiae and preterm birth, low birth weight and premature rupture of membranes. These results, however, were often contradictory, and most of the work was based on a very small group of patients. In a study of over 13,000 women, conducted in 7 countries, the relations between the streptococcal colonization gr. B and unfavourable outcome of pregnancy was assessed [23]. It was found that severe colonization significantly more likely is to be observed in older women during labour, and increases the likelihood of premature birth as well as low birth weight of a newborn (less than 2,500g).

After the implementation of the universal GBS screening programme, only 2 factors, including a positive result of GBS screening and preterm birth affect the morbidity for neonatal early-onset [24]. Hickman et al. have shown that the risk of early sepsis of GBS etiology grows with extension of time from the point of interruption of the membranes to the birth of the foetus. Hickman also showed that the colonization of infants born to mothers who are carriers of GBS, with the rupture amniotic membrane in less than 12 hours, fluctuates around $38 \%$ and rises to $73 \%$ when the time from rupture of amniotic membrane is more than 12 hours [25].

In the current study, a transcriptomic and proteomic assessment of GBS cultured in the presence vel absence of bilirubinwe was additionally performed. Analysis revealed that increasing levels of bilirubin negatively correlated with GBS growth [26]. Studies by Hijona et al. seem to be optimistic. They observed significantly smaller GBS colonization in patients receiving dequalinium chloride (DQC), 10mg vaginal tablets just before delivey [27].

\section{CONCLUSIONS}

The use of maternal antibiotic prophylaxis may have the effect of lowering the percentage of GBS infections in newborns. The proportion of early-symptomatic infections has decreased in the interval of consecutive years. The type of birth does not seem to have a decisive impact on the incidence of infection with GBS etiology. The colour of the amniotic fluid does not determine the presence of GBS infection.

\section{REFERENCES}

1. Kotarski J, Heczko PB, Lauterbach R, Niemiec T, Leszczyńska-Gorzelak B. Rekomendacje Polskiego Towarzystwa Ginekologicznego dotyczące wykrywania nosicielstwa paciorkowców grupy B (GBS) u kobiet w ciąży i zapobiegania zakażeniom u noworodków. Ginekol Pol. 2008; 79: 221-223.

2. Centers for Disease Control and Prevention (CDC). Perinatal group $\mathrm{B}$ streptococcal disease after universal screening recommendationsUnited States, 2003-2005. MMWR Morb Mortal Wkly Rep 2007; 56: 701-705.

3. Barcaite E, Bartusevicius A, Tameliene R, Kliucinskas M, Maleckiene L, Nadisauskiene R. Prevalence of maternal group B streptococcal colonisation in European countries. Acta Obstet Gynecol Scand. 2008; 87(3): 260-271.

4. Pettersson KS. Perinatal infection with group B sterptococci. Semin Fetal Neonatal Med. 2007; 12: 193-197.

5. Boyer KM, Gadzala CA. Selective intrapartum chemoprophylaxis of neonatal group B streptococcal early-onset disease. I Epidemiologic rationale. J Infect Dis. 1983; 148: 795-801.

6. Baltimore RS. Consequences of prophylaxis for group B streptococcal infections of the neonate. Semin Perinatol. 2007; 31: 33-38.

7. Renner RM, Renner A, Schmid S, Hoesli I, Nars P, Holzgreve W, [et al.]. Efficacy of a strategy to prevent neonatal early-onset group B streptococcal (GBS) sepsis. J Perinat Med. 2006; 34: 32-38.

8. Centers for Disease Control and Prevention (CDC). Trends in perinatal group B streptococcal disease-United States, 2000-2006. MMWR Morb Mortal Wkly Rep. 2009; 58: 109-112.

9. Velaphi S, Siegel J, Wendel G. Early-Onset Group B Streptococcal Infection After a Combined Maternal and Neonatal Group B Streptococcal Chemoprophylaxis Strategy. Pediatrics. 2003; 111: 541-547.

10. Puopolo KM, Madoff LC, Eichenwald EC. Early-onset group B streptococcal disease in the era of maternal screening. Pediatrics. 2005; 115 : 1240-1246.

11.Schrag SJ, Verani JR. Intrapartum antibiotic prophylaxis for the prevention of perinatal group B streptococcal disease, experience in the United States and implications for a potential group B streptococcal vaccine. Vaccine. 2013; 31(4): D20-26.

12. Valkenburg-van den Berg AW, Houtman- Roelofsen RL, Oostvogel PM, Dekker FW, Dörr PJ, Sprij AJ. Timing of group B streptococcus screening in pregnancy, a systematic review. Gynecol Obstet Invest. 2010; 69: 174-183.

13. Berardi A, Lugli L, Baronciani D, Rossi C, Ciccia M, Creti R. GBS Prevention Working Group of Emilia-Romagna. Group B Streptococcus early-onset disease in Emilia-Romagna, review after introduction of a screening-based approach. Pediatr Infect Dis J. 2010; 29: 115-121.

14. Boyer KM, Gadzala CA, Burd LI, Fisher DE, Paton JB, Gotoff SP. Selective intrapartum chemoprophylaxis of neonatal group B Streptococcal earlyonset disease. J Infect Dis. 1983; 148: 802-809.

15. Assefa S, Desta K, Lema T. Group B streptococci vaginal colonization and drug susceptibility pattern among pregnant women attending in selected public antenatal care centers in Addis Ababa, Ethiopia. BMC Pregnancy Childbirth. 2018; 18:135.

16. Feng-Ying C, Leonard EW, Parvin A, Young AE, Chang K, Cielo M, [et al.]. Assessment of Intrapartum Antibiotic Prophylaxis for the Prevention of Early-onset Group B Streptococcal Disease. Pediatr Infect Dis J. 2011; 30: 759-763.

17. Bauserman MS, Laughon MM, Hornik CP, Smith PB, Benjamin Jr. DK, Clark RH, [et al.]. Evaluation of Universal Antenatal Screening for Group B Streptococcus. N Engl J Med. 2009; 360: 2626-2636.

18. Pulver LS, Hopfenbeck MM, Young PC, Stoddard GJ, Korgenski K, Daly J. Continued early onset group B streptococcal infections in the era of intrapartum prophylaxis. J Perinatol. 2009; 29: 20-25.

19. El Helali N, Nguyen JC, Ly A, Giovangrandi Y, Trinquart L. Diagnostic accuracy of a rapid real-time polymerase chain reaction assay for universal intrapartum group B streptococcus screening. Clin Infect Dis. 2009; 49: 417-423.

20. Honest H, Sharma S, Khan KS. Rapid tests for group B Streptococcus colonization in laboring women, a systematic review. Pediatrics. 2006; 117: 1055-1066.

21. Money D, Dobson S, Cole L, Karacabeyli E, Blondel-Hill E, Milner R, [et al.]. An evaluation of a rapid real time polymerase chain reaction assay for detection of group B streptococcus as part of a neonatal group B streptococcus prevention strategy. J Obstet Gynaecol Can. 2008; 30: $770-775$. 
22. Ohlsson A, Shah V. Intrapartum antibiotics for known maternal Group B streptococcal colonization. Cochrane Database Syst Rev. 2009; 3, CD007467.

23. Regan JA, Klebanoff MA, Nugent RP. The epidemiology of group $B$ streptococcal colonization in pregnancy. Vaginal infections and Prematurity Study Group. Obstet Gynecol. 1991; 77: 604-610.

24. Hung L, Kung PT, Chiu TH, Su HP, Ho M, Kao HF, [et al]. Risk factors for neonatal early-onset group B streptococcus-related diseases after the implementation of a universal screening program in Taiwan. BMC Public Health 2018; 18: 438.
25. Hickman ME, Rench MA, Ferrieri P, Baker CJ. Changing epidemiology of group B streptococcal colonization. Pediatrics. 1999; 104: 203-209. 26. Hansen R, Gibson S, Alves E, Goddard M, MacLaren A, Karcer AM, [et al.] Adaptive response of neonatal sepsis-derived Group B Streptococcus to bilirubin. Sci Rep. 2018; 8: 6470.

27. Hijona JJ, Carballo AL, Sanchez MS, Dyachkova N, Exposito JF, Alcazar JL. Vaginal antiseptics reduce the risk of perinatal infection with group B streptococci. J Matern Fetal Neonatal Med. [published online 26apr 2018] DOI: $10.1080 / 14767058.2018 .1449196$. 